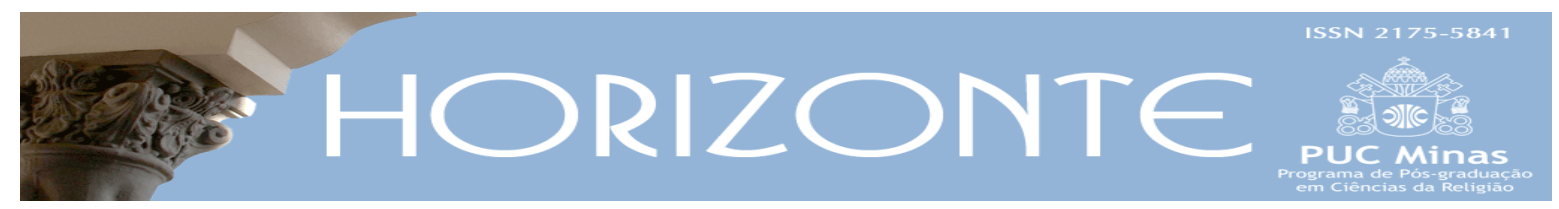

Temática Livre - Tradução @-

\title{
O pluralismo da verdade
}

\author{
The pluralism of truth
}

Raimon Panikkar*

Tradução de Rita Macedo Grassi**

Originalmente publicado na revista World Faith Insights, n. 26, p. 7-16, 1990, este texto é a transcrição de uma palestra proferida pelo teólogo e filósofo catalão Raimon Panikkar (1918-2010). ${ }^{1}$

Por se tratar de uma transcrição fiel da linguagem oral, nosso desafio nesta tradução foi adequar o texto à linguagem escrita sem, no entanto, perder os traços característicos do palestrante e autor.

\footnotetext{
Texto submetido em 15 de abril de 2019 e aprovado em 15 de fevereiro de 2020.

* Raimon Panikkar (1918-2010) é hoje reconhecido como um dos corifeus contemporâneos do diálogo inter-religioso.

** Doutoranda em Sciences Religieuses na École Pratique des Hautes Études, na Paris Sciences et Lettres. Mestra em Ciências da Religião pelo PPGCR PUC Minas. País de origem: Brasil. E-mail: ritagrassi2010@gmail.com

${ }^{1}$ A versão original do texto, em língua inglesa, encontra-se disponível em:

http://www.dhdi.free.fr/recherches/horizonsinterculturels/articles/panikkarpluralism.pdf
} 


\section{Nossa situação humana}

\subsection{0 panorama geográfico}

Permitam-me refletir sobre a desordem geográfica do mundo moderno. Há mais de um século, 80 por cento das pessoas não se movia mais do que 50 milhas ${ }^{2}$ dos seus locais de nascimento. Atualmente, na América do Norte, todas as famílias trocam de domicílio a cada 4 anos e meio. O Attântico é cruzado por milhões de pessoas. Em oito horas você pode estar em Katmandu e, aqui hoje, há um público de uma enorme variedade de raças, idiomas e religiões. A desordem geográfica aumenta a mistura de povos e culturas, mas, também, as tensões e as contendas. Agora, nós nos misturamos, estamos prontos para tolerar o outro, não nos escandalizamos mais com nada. Imitamos, rejeitamos, nos aborrecemos; mas, no fim das contas, temos que concordar e suportar o máximo que pudermos. Buscamos encontrar nosso caminho nesta selva de variedades de todos os tipos de opiniões e comportamentos. Somos forçados a lidar uns com os outros e, assim, apesar das nossas respectivas máscaras (de autodefesa), somos praticamente obrigados a tentar compreendermo-nos uns aos outros.

\section{A questão da compreensão}

Antigamente, as pessoas percebiam que elas não se compreendiam. As pessoas percebiam que elas não compreendiam aqueles indivíduos exóticos, aqueles hábitos estranhos, e aquelas religiões estrangeiras. Mas, como elas não os encontravam todos os dias, não era um grande desafio. Os estrangeiros viviam em países lindos, em selvas primitivas, ou em guetos negligenciados, mas sempre longe, geograficamente ou espiritualmente. De vez em quando, antropólogas e antropólogos 3 nos contavam histórias, que achávamos mais ou menos interessantes, engraçadas ou irritantes. Os conflitos aconteciam apenas entre

\footnotetext{
${ }^{2}$ Aproximadamente, 50 quilômetros.

${ }^{3} \mathrm{Em}$ inglês, a palavra "anthropoligists" não tem definição de gênero, portanto, optamos por traduzi-la tanto no masculino quanto no feminino.
} 
religiões 4 vizinhas, frequentemente relacionados a questões de ordem econômica ou política; ou entre intelectuais preocupados com os resultados negativos de divergências religiosas.

Agora, os problemas estão diante dos nossos olhos e nós precisamos compreendê-los. Por favor, tenham paciência comigo pelo único trocadilho filosófico em inglês que eu me permito fazer: compreender5 é colocar-se sob o fascínio da coisa a qual compreendemos; significa deixar-se fascinar pela coisa, e colocar-se abaixo dela em admiração ou, até mesmo, com ceticismo. É uma atitude existencial, nós nos colocamos sob o poder do arriscado ato do conhecimento (inter-legere). Conhecer, conforme explicitado pelas Upanixades e por Tomás de Aquino (seguindo Aristóteles), significava identificar-se com o conhecido. Atualmente, devido à mudança de significado da noção de conhecimento, introduzida e popularizada pelas chamadas ciências naturais modernas, compreender foi reduzido a ser capaz de prever, calcular e dominar. Em resumo, afirmamos compreender ao colocarmo-nos acima da coisa ${ }^{6}$. Se nos colocamos acima, simplesmente aplicamos as nossas próprias categorias ou superestruturas. Nós os sobrepomos para podermos reconhecer o objeto, e não mais compreender a coisa. Será que deveria inserir aqui uma nota de rodapé sobre as categorias kantianas e a crítica ante litteram de Shankara com a sua noção de adhyâsa (superimposição)?

Estou apenas preparando o terreno para indicar que há um problema epistemológico inevitável subjacente à nossa questão.

Se "nos colocamos acima", como um "conhecimento" científico pretensamente universal, abordamos a realidade de uma perspectiva superior àquela das coisas mesmas. Não estamos ouvindo as coisas, submetendo-nos a elas; estamos integrando objetos ao nosso esquema mental. "Colocamo-nos acima"7 de

\footnotetext{
${ }^{4}$ Embora na transcrição original esteja escrito a palavra "religions", desconfiamos que o autor desejasse dizer "regions", ou seja, regiões. Mas, optamos por utilizar a mesma palavra do original.

${ }^{5}$ Aqui ele faz um trocadilho com o verbo to understand que, se separado, pode significar "colocar-se sob algo" (under-stand).

"Ele conclui o trocadilho criando a palavra "overstanding", que pode significar "colocar-se acima de algo".

${ }^{7}$ Novamente, aqui, ele utiliza o verbo "to overstand".
} 
uma plataforma mais alta: Razão, Ciência, Revelação, ou qualquer coisa, a qual, obviamente, "nós" tenhamos acesso privilegiado. A inteligibilidade vem, então, de um único princípio superior. Por outro lado, se nós verdadeiramente compreendermos, devemos humildemente reconhecer que, enquanto nós temos acesso a uma fonte de inteligibilidade, outras pessoas podem beber de outras fontes também, ou em outros riachos da mesma fonte. A história humana tem nos mostrado que o Homem tem muitas autocompreensões diferentes. Podemos passar por cima das diferentes autocompreensões humanas através, exclusivamente, da nossa interpretação? Podemos reconhecer objetos, mas aqui temos que lidar não com objetos, mas com o Homem, cuja própria natureza é ser dotado de autocompreensão. Então, conhecer o Homem inclui conhecer as suas autocompreensões - e não somente a nossa interpretação de um objeto chamado antropos. Esse é o problema.

Algo aconteceu com um Siciliano no início do século. Ele foi preso, levado ao tribunal, algemado. Parece que ele era inocente, mas não pronunciou uma palavra sequer quando o juiz solicitou que se defendesse. Quando o advogado lhe perguntou, depois, por que não havia falado, ele disse: "Como eu poderia falar se as minhas mãos estavam presas?”. Para o Siciliano, a palavra ainda era algo além do seu significado: era gesto. Como ele poderia falar sem usar as mãos ao mesmo tempo que sua língua?

\section{Uma compreensão universal?}

Já sofremos no passado, e ainda sofremos tanto, por causa dos fanatismos políticos, religiosos e culturais, que estamos legitimamente sedentos por uma compreensão universal. Um exemplo típico dessa mentalidade é a síndrome da aldeia global. Apesar da intenção ser nobre, para mim soa como apenas mais uma valiosa sucessora da mentalidade colonialista. O colonialismo acredita no monomorfismo da cultura; que haja, fundamentalmente, apenas uma civilização: "E, agora, vem a unificação do mundo em uma aldeia global. Agora, nós podemos ter uma teologia universal que fará um pequeno buraco confortável para os 
mulçumanos, outro para os descrentes, e todo mundo será feliz, porque agora somos tolerantes, não forçamos nada, aceitamos tudo e todos têm o seu lugar. Todos podem dar as boas-vindas a uma teologia universal que é baseada na abertura, na tolerância, e na autocrítica.” Até aqui tudo bem, mas é assim tão fácil estar realmente aberto ao fanático, ser tolerante com o intolerante, e aceitar a crítica daqueles que não concordam com a nossa teologia universal?

Ainda que haja uma sede pela real compreensão, não podemos viver compartimentalizados. O outro se torna um problema precisamente porque invade a minha vida e é irredutível às minhas visões. Se um extremo é que estamos todos certos e os outros errados, o outro extremo é que nós todos cabemos em um tipo de aldeia global. Permito-me afirmar que não foi dado a nenhum de nós abarcar a gama universal da experiência humana. Em uma aldeia, todos se conhecem e as diferentes dialéticas são compreendidas. Ainda sonhamos que uma televisão universal fará uma verdadeira "comunicação" para 5,2 bilhões de pessoas? Existe uma inércia da mente muito visível na maioria dos esforços para lidar com esse problema. Tenho a sensação que devemos encarar uma visão radicalmente nova da realidade.

Esse é o desafio.

\section{Pluralismo}

Entre esses dois extremos, a palavra "pluralismo" tem emergido, cada vez mais, como representante de uma terceira atitude; e este é o segundo ponto da minha apresentação.

\section{Pluralismos aceitos}

Há uma série de pluralismos que são aceitos hoje em dia. Um filósofo pode ser um bom filósofo, e não necessariamente ser um seguidor de Kant ou de quem quer que seja. Um filósofo pode discordar do outro e, ainda assim, ambos serem aceitos como bons filósofos. O pluralismo da filosofia é aceito. O pluralismo 
teológico é, também, praticamente reconhecido. O pluralismo cultural também é algo do qual nos gabamos, embora não considere que o tenhamos alcançado. O que temos é um certo tipo de tolerância cultural que permite que gregos, paquistaneses e ciganos tenham seus próprios folclores - mas todos eles têm que pagar impostos... e aceitar as nossas Leis e Constituições. Estamos teoricamente prontos para aceitar o pluralismo cultural a qualquer custo. O pluralismo religioso, que não pode ser separado do pluralismo cultural, é provavelmente a última e mais difícil noção a aceitar. Ela atinge a nossa identidade pessoal.

\section{As preliminares do pluralismo}

Precisamos estar conscientes da pluralidade. Isto é um fato. Mas pluralidade ainda não é pluralismo. Pluralidade é o reconhecimento de diferentes modos, cores. É uma noção quantitativa.

Um segundo passo é a pluriformidade. Não há apenas diferenças, mas também variedade. Esta é uma noção qualitativa. Nos tornamos sensíveis às variedades para as quais não podemos dar uma medida quantitativa. Azul não é verde e não há como dizer que o verde seja mais bonito do que o azul. Não podemos medir o que é melhor, o que é mais bonito, e isso depende do contexto. Mas ainda não é pluralismo.

O pluralismo dá um passo além do reconhecimento das diferenças (pluralidade) e das variedades (pluriformidade). O pluralismo tem a ver com a diversidade radical. Este próximo passo teve dois precursores.

O primeiro passo é o perspectivismo. Aqueles familiarizados com a fábula indiana do elefante em um lugar escuro, lembram-se que alguém disse que era algo como um osso, outros disseram que era uma pilastra pesada, um container largo, uma pele grossa e coisas assim. Esse seria um exemplo de perspectivismo. Perspectivismo é o senso comum. As pessoas veem de diferentes perspectivas e nós temos que respeitá-las. A dificuldade é, como em nosso exemplo, que alguém tem que saber que se trata de um elefante. Quando eu conheço o elefante, posso dizer 
que você está simplesmente descrevendo a presa, você a pata, e você um outro membro, mas se ninguém conhece o elefante, como iremos defender o perspectivismo? Obviamente, "nós" os vedantinos, os cristãos, os cientistas... "Nós" conhecemos o elefante!

O segundo passo é a relatividade, que não deve ser confundida com o relativismo. O relativismo anula o seu objetivo. Relativismo é agnosticismo autodestrutivo. Você nem pode saber que você não sabe. Se não há um critério para o discernimento, o relativismo também não é um critério. A relatividade, por outro lado, é algo bem mais sério. A relatividade nos diz que tudo depende de uma coleta de dados, através dos quais aquela hipótese, afirmação, fato, ou situação específicos possam ser expressados; mas, também, falsificados, verificados ou algo assim. Abole qualquer tipo de pretensão absolutista. Mas, ouso dizer que, o pluralismo no seu sentido mais profundo dá um passo além e é isso que ainda gostaria de descrever de forma resumida.

\section{Descrição de pluralismo}

Tentarei resumir o quero dizer em seis pontos:

1. Pluralismo não significa pluralidade ou uma redução da pluralidade em unidade. É um fato que há uma pluralidade de religiões. Também é um fato que essas religiões não podem ser reduzidas a nenhum tipo de unidade. Pluralismo significa algo mais do que puramente um reconhecimento da pluralidade e o mero desejo por unidade.

2. O pluralismo não considera a unidade um ideal indispensável, mesmo que se permita variações dentro dessa unidade. O pluralismo aceita aspectos irreconciliáveis das religiões sem estar cego para os aspectos comuns. O pluralismo não é a expectativa escatológica de que no fim todos serão um. 
3. O pluralismo não permite um sistema universal. Um sistema pluralista seria, em termos, uma contradição. A incomensurabilidade de sistemas definitivos é intransponível. Essa incomensurabilidade não precisa ser um mal menor, mas poderia ser, ela mesma, uma revelação da natureza da realidade. Nada pode abarcar a realidade.

4. O pluralismo nos torna conscientes da nossa contingência e da nãotransparência da realidade. É incompatível com a suposição monoteísta de um Ser totalmente inteligível, ou seja, de uma consciência onisciente identificada com o Ser. No entanto, o pluralismo não foge da inteligibilidade. A atitude pluralista tenta alcançar a inteligibilidade o máximo possível, mas não necessita do ideal de uma compreensão total do real.

5. O pluralismo é um símbolo que expressa uma atitude de confiança cósmica que permite uma coexistência tensa e polarizada entre as atitudes humanas fundamentais, cosmologias e religiões. Não elimina nem absolutiza o mal e o erro.

6. O pluralismo não nega a função do logos e os seus direitos inalienáveis. O princípio da não-contradição, por exemplo, não pode ser eliminado. Mas, o pluralismo também pertence à ordem do mythos. Incorpora o mythos, não, é claro, como um objeto do pensamento, mas como um horizonte que torna o pensar possível. A brevidade me compele a não desenvolver esses pontos como já fiz em outros lugares.

\section{0 pluralismo da verdade}

\subsection{A verdade está além da unidade e da pluralidade}

O pluralismo não afirma que a verdade seja uma e nem que seja muitas. Se a verdade fosse uma, nós não poderíamos aceitar a tolerância positiva de uma atitude pluralista e teríamos que considerar o pluralismo uma conivência com o erro. Poderíamos, na melhor das hipóteses, evitar qualquer julgamento a respeito de questões irrelevantes e duvidosas. Mas, como podemos nos abster de condenar o 
que julgamos mal ou erro? Como podemos adiar decisões práticas, ainda mais quando o mero adiamento já é uma decisão acrítica?

Mas, a verdade também não é múltipla. Se houvessem várias verdades, cairíamos numa simples contradição. Já dissemos que o pluralismo não defende a pluralidade, a pluralidade da verdade nesse caso. O pluralismo adota uma atitude não-dualista ou advaita que defende o pluralismo da verdade porque a própria realidade é pluralista, isto é, incomensurável tanto pela unidade quanto pela pluralidade. Sendo assim, mesmo se abarcada por, ou coexistente com o logos ou com uma inteligência suprema, não precisa ser reduzida à consciência. De fato, a verdade é o autoespelhamento perfeito do Ser, mas, mesmo que a perfeita imagem do Ser seja idêntica ao Ser, o Ser não precisa estar restrito a sua imagem - ao menos que se assuma previamente que o Ser seja (apenas) Consciência.

\section{A verdade não tem centro}

Há interessantes discussões nos círculos teológicos sobre se o cristocentrismo, ou o teocentrismo, ou qualquer outro centro, deveria ser o ponto de referência para a teologia cristã. Nos círculos sociológicos e antropológicos, são debatidas questões sobre o etnocentrismo, atitudes Eurocêntricas, e o tecnocentrismo. Todas essas discussões, implicitamente, reconhecem que tem de haver um centro, se tivermos que alcançar a inteligibilidade. O centro, se é que existe, é móvel. Digo para "cristocentristas" e "teocentristas" a mesma coisa: "Você está certo!". Mas, enfatizo o "você”, o contexto a partir do qual o teólogo específico pensa. $\mathrm{O}$ que não é necessariamente verdadeiro é que a verdade necessite sempre do mesmo centro.

Deixem-me citar a história do sábio rabino que estava presidindo uma congregação há tempos atrás. Os judeus estavam brigando uns contra os outros, e uma das partes foi expor suas queixas ao rabino, que disse: "Vocês estão certos! Vocês estão certos!”. A outra parte da congregação, quando soube daquilo, foi também ao rabino e explicou sua posição. O rabino ouviu atentamente e disse: "Vocês estão certos! Vocês estão certos!". Obviamente, a briga recomeçou. Então, 
os intelectuais e escribas da congregação, que sabiam mais, formaram uma pequena comissão e foram respeitosamente até o rabino e disseram: "Mestre, você disse hoje que isso está certo, e ontem que a outra parte estava certa. Obviamente que ambos não podem estar certos." O rabino disse: "Vocês estão certos! Vocês estão certos!”. Quem está certo? Ou apenas o rabino está errado?

A relação entre as três afirmações é claramente dialética. Mas a relação entre os dois grupos de pessoas vivas que estavam discutindo não é dialética. O rabino enxergou a complementaridade relativa de cada posição, embora envolvesse a contradição mútua das afirmações intelectuais, conforme observou a terceira parte, que não estava existencialmente envolvida.

O que estou tentando dizer é que o pluralismo acontece quando descobrimos a mútua incomensurabilidade das atitudes humanas. É o reconhecimento da incompatibilidade de crenças definitivas. Devemos levar a sério as experiências e esforços dos últimos 8.000 anos de memória histórica, cada parte pensando estar fazendo a coisa certa, e a outra acreditando que não é bem assim. Devíamos ouvir mais uma vez a sabedoria de Salomão. Nossas muitas soluções querem partir a criança ao meio, quando não podemos tê-la para nós. A verdade, como a criança, é nossa. Mas para manter a criança viva, para manter a humanidade viva, para manter a polaridade das realidades humanas vivas, para manter a boa fé das pessoas viva, para manter viva a liberdade como a mais alta dignidade, não podemos julgar apenas pela Razão. Salomão nos mostrou que o seu julgamento final estava correto, porque quando o amor intervém, quando a criança é sua, você prefere perdê-la; você prefere mesmo ser pisoteado, mas a criança tem que sobreviver. Entendo que a nossa situação presente requer de todos nós a capacidade de dizer: "Eu não te compreendo muito bem e até penso que você esteja errado, mas o fato de você estar errado não me diz muito sobre o fato de eu estar certo, ou talvez de que eu também esteja errado.”

Precisamos dessa relação uns com os outros. Este encontro "inter-religioso" não é apenas uma relação dialética. Também requer amor, diálogo, e toque humano. Estamos interligados, mesmo que as nossas noções e códigos sejam 
incompatíveis. O raio e a circunferência estão interligados mesmo que sejam mutuamente incomensuráveis. O pluralismo está interligado à condição humana.

\section{A verdade é polar}

A compreensão de que a verdade é pluralista pode ser descrita ao dizer que a própria natureza da verdade é polar. A verdade pela verdade é em si mesma uma polaridade. Não importa qual teoria filosófica nós adotemos (correspondência, coerência, pragmática e outras), uma coisa permanece comum a todas. A verdade é sempre uma relação, seja entre sujeito/objeto, ou sujeito/predicado, ou conhecedor/conhecido, ou usuário/usado, etc. Ainda há mais. Um dos termos da relação, explicitamente ou implicitamente, somos nós. Homens. Mesmo se falarmos da verdade metafísica do Ser ou da verdade teológica da própria Divindade, nós humanos não podemos ser totalmente excluídos. E este é, ainda mais, o caso quando lidamos com a verdade religiosa. Estamos convolvidos no processo. Em outras palavras, a verdade tem sempre um elemento de subjetividade no sentido de que nós, Homens, estamos de alguma forma partilhando daquela afirmação, entidade, processo, ou situação que chamamos de verdade. A verdade é sempre uma relação que se refere a nós Homens, para os quais a verdade é verdade (e não apenas objetivamente verdade).

Agora, se o juiz sou apenas eu, ou somos nós, em uma cultura específica no espaço-tempo, este eu ou este nós não pode esgotar a relação inteira. Isso por duas razões: primeiro, este eu ou nós é limitado e nunca pode saber se conhece inteiramente o outro lado da questão. Segundo que, o sujeito (eu, nós) é em si mesmo não-objetivável e sem nenhuma garantia de que não irá mudar. Somos um dos polos da relação, e não podemos ter certeza de que não poderemos mudar. Não podemos ter controle de nós mesmos exceto de um polo objetivo, que por sua vez está relacionado ao polo subjetivo. Um exemplo claro é a chamada evolução do dogma. Se os sujeitos mudam suas percepções e pressuposições, consequentemente, as "verdades objetivas" do dogma também precisam mudar, precisamente para manter constante a relação. 
Se este juiz não for um "nós" mas um intelecto infinito, além do fato de que só podemos ter uma limitada interpretação humana desta inteligência absoluta, não há também qualquer necessidade de que este intelecto infinito conheça todo o Ser. Não há nada escondido para uma inteligência infinita; ela é onisciente e, como tal, o que ela sabe é a Verdade. Alguém pode até alegar que é a própria fonte da verdade, já que a verdade é precisamente o que o intelecto divino sabe. A verdade estaria então originalmente ao lado do Sujeito, não estando condicionada a nenhum objeto. Isso estaria, ainda mais, a favor de um pluralismo da verdade, pois a Verdade dependeria completamente do Prazer Divino e não haveria qualquer parâmetro objetivo para a persistência de uma "mesma" verdade; ou ainda, essa "mesma" verdade seria despida de qualquer ponto de referência para afirmar-se como tal. Não poderíamos dizer se a verdade é uma ou se são várias.

A posição tradicional defenderá que a verdade é uma, porque este intelecto infinito não pode mudar. Essa linha argumentativa já infere a identificação do Ser com a Consciência. Mas, essa é uma suposição gratuita não garantida pela aceitação de uma Consciência infinita. A Consciência divina, de fato, deveria saber Tudo, isto é, tudo o que pode ser conhecido, mas não tudo que não é tudo (do) Ser; a não ser que identifiquemos previamente Ser com Consciência. Uma inteligência infinita não tem limites no seu próprio campo: nada é ininteligível para ela, mas este campo não precisa ser totalmente idêntico à realidade. Resumindo, pode muito bem ser que a Realidade tenha uma face obscura, impenetrável pela Inteligibilidade. Em linguagem cristã, a Divindade não pode ser reduzida a um Logos infinito. "Há" também uma Fonte apofática. Há também o Espírito, que não é inferior ou diferente do Logos, mas também não é redutível a ele. A Verdade de Deus, o logos, paradoxalmente, não é Todo o Deus, porque Deus sendo Verdade, Logos, e Verdade infinita, Deus "é" apenas isso. "É" Trindade.

Poderíamos formular o pluralismo da verdade de uma maneira mais iogue ou budista. Comentaríamos então sobre o citta-vrttinirodha, ou cessação de toda atividade mental, como no início do Yogasûtra, ou no àkimcanya âyatana, ou a morada da não-existência, como no budismo primitivo. Em ambos os casos, o 
mental é superado e a compreensão definitiva está além da dialética tetralêmica (do $\mathrm{A}$, não $\mathrm{A}, \mathrm{A}$ e não $\mathrm{A}$, nem $\mathrm{A}$ nem não $\mathrm{A}$ ). A verdade não é abolida, mas a sua morada (âyatana) não é mais a mansão da linguagem. Você é tão estúpido para realmente acreditar que a sua opinião é correta e todas as outras estão erradas, insinua discretamente a Suttanipâta.

Essas últimas considerações são apenas formas de linguagem de escolas específicas. E ainda, quase todas as teologias, como ressaltou tão claramente Ibn 'Arabi em sua jam' al-diddayn (coincidentia oppositorum), são forçadas a utilizar linguagem antinômica e paradoxos quando referem-se ao Divino: a verdade de uma afirmação tem que ser contradita por uma outra afirmação, que é igualmente verdadeira. A verdade não pode ter uma expressão única e unívoca, ressaltou alchaykh al akbar (o grande mestre), como a tradição o chamava. Esse poderia ser um exemplo do nosso ponto, que está diretamente relacionado com a questão da verdade religiosa, no próprio encontro entre as religiões. Deixem-me relatar alguns dos corolários, sem agora elaborar sobre a intrínseca polaridade da verdade e sobre o fato de que estamos, no mínimo, parcialmente envolvidos em um dos polos.

\section{Por via de conclusão}

O pluralismo da verdade compreende, entre outros corolários:

1. A verdade religiosa de uma tradição específica pode ser apropriadamente compreendida somente dentro da própria tradição que a elaborou. Cada tradição tem a sua linguagem.

2. A partir de um sistema intelectual religioso, pode-se legitimamente criticar um outro sistema, considerando-se que se chega a algum ponto em comum, onde o diálogo e a crítica possuem um significado para ambas as partes. Nós precisamos falar, ao menos parcialmente, uma linguagem em comum.

3. Em qualquer momento da história humana, há mitos prevalecentes que permitem uma crítica intercultural e transreligiosa das opiniões mantidas. $\mathrm{O}$ 
sacrifício humano e a escravidão podem ser justamente apontados por terem provocado um consenso universal que justifica chamá-los de errados imediatamente. Mas há, hoje, assuntos urgentes que não devem ser minimizados por uma abordagem meramente intelectual. A não ser que nos esquivamos das palavras, a violência deve ser evitada a qualquer custo? Deus é uma hipótese necessária para um mundo justo? O capitalismo atual é uma força desumana? Podemos ter fortes opiniões sobre essas questões, mas não devemos apresentá-las como "verdades" inegociáveis.

O pluralismo da verdade é um abridor de olhos, em primeiro lugar, para a contingência; eu não tenho uma visão de 360 graus; ninguém tem. Em segundo lugar, e esta é a noção mais desafiadora, a verdade é pluralista porque a própria realidade é pluralista, e não uma entidade objetivável. Nós sujeitos também somos parte disso. Não somos apenas espectadores do Real, também somos coatores e até mesmo coautores dele. Essa é precisamente a nossa dignidade humana.

Sinto que este pequeno esboço, ainda que imperfeito, toca em uma questão essencial sobre a própria natureza da Realidade, e ao tocar na natureza da Realidade repercute, por assim dizer, na natureza de todos os acontecimentos. Este terceiro milênio do mundo Ocidental, aponta para uma mutação da nossa situação, e requer de nós uma noção do que significa ser humano, do que significa ser divino, do que é o mundo no qual vivemos e pelo qual nós compartilhamos a responsabilidade. 